\title{
Is overweight and obesity in 9-10-year-old children in Liverpool related to deprivation and/or electoral ward when based on school attended?
}

\author{
Trevor JB Dummer ${ }^{1}$, Mark A Gibbon ${ }^{2}$, Allan F Hackett ${ }^{2, *}$, Gareth Stratton ${ }^{1}$ \\ and Sue R Taylor ${ }^{2}$ \\ ${ }^{1}$ Liverpool John Moores University, Henry Cotton Campus, Liverpool, UK: ${ }^{2}$ Liverpool John Moores University, \\ IM Marsh Campus, Barkhill Road, Liverpool L17 6BD, UK
}

Submitted 14 September 2004: Accepted 6 January 2005

\begin{abstract}
Objectives: To determine whether weight problems in children (overweight, obesity and overweight or obesity) were related to deprivation indices when attributed only according to electoral ward of the school attended. To determine whether children with weight problems were more likely to be found in some wards rather than others, and to compare the distribution for boys and girls.

Design: Retrospective, cross-sectional, observational study.

Setting: One hundred and six primary schools from all parts of Liverpool city.

Subjects: Five cohorts of 9-10-year-old children between 1998 and 2003.

Main outcome measures: Body mass index (BMI) for each child to estimate proportions overweight, obese and overweight or obese according to international criteria.

Results: Between January 1998 and March 2003, the heights and weights of 7902 boys and 7514 girls were measured and BMI calculated. The prevalence of boys and girls categorised as overweight or obese was very high (1620, 20.6\% and 1909, 25.7\%, respectively). Prevalence was not related to deprivation and varied between wards only for the girls; some wards had very different prevalence rates for boys and girls (Picton: 59 boys, 23.4\%; 106 girls, 36.6\%). The most deprived ward did not have a remarkable prevalence of overweight or obesity (Speke: 32 boys, 15.3\%; 40 girls, $19.8 \%)$.

Conclusions: Obesity is a major problem and requires urgent action but targeting intervention on the basis of administrative areas may be very wasteful. Different factors seem to lead to obesity in boys and girls, and attention should be paid to the role of the physical environment.
\end{abstract}

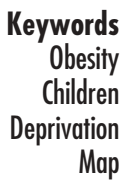

Most adults in the UK are now overweight or obese ${ }^{1}$ The proportion of children with inappropriately high body weight is high and increasing, and there is no immunity for sex or age group, race or education status ${ }^{2}$. The health risks associated with excess body weight are well known and are a threat to individuals, health-care services and the economic health of the nation. The causes of this epidemic are simple in principle (more energy is being consumed than is being expended on a chronic basis) but very complex in practice (a huge number of factors conspire to create an obesogenic environment where it is the norm to eat excessively and avoid physical activity). In particular, the diets of children are characterised by high intakes of sugar, fat and salt, and intakes of fibre, unrefined carbohydrates and fruit and vegetables below recommendations ${ }^{3}$.
Likewise, patterns of physical activity in children indicate a sedentary lifestyle for many ${ }^{4}$.

The Government has been slow to react: targets on obesity were set in $1992^{5}$ but not revised in the New Labour policy $^{6}$. Initiatives have begun, such as fruit in schools, but there is evidence that ministers do not understand the complexity of the issue $e^{7}$. Government policy focuses on addressing the marked inequalities in health along socioeconomic lines. This has led to many schemes being targeted on geographical areas judged to be deprived; for example, the setting up of Health Action Zones. Primary care trusts (PCTs) have the responsibility for public health and hence data must be collected at a local level, a problem aggravated by PCT and local authority boundaries and other administrative units not being co-terminus. This raises the two questions addressed in this paper: is obesity 
simply related to 'deprivation' when defined by administrative area and school attended and is obesity concentrated in some geographical areas (electoral wards)?

A summary of overweight and obesity in European children shows huge differences between countries (10\% in Slovakia, 36\% in Italy and in the $22 \% \mathrm{UK}^{8}$. Within the UK, body mass index (BMI) does not vary by region in adults $^{9}$ or in young people $\mathrm{e}^{10}$ and whether obesity is more prevalent in more local areas is uncertain. If so, elements of the obesogenic environment susceptible to change might be identified, although this may be unlikely ${ }^{11}$.

The relationship between obesity and socio-economic status or deprivation is unclear. Overall, women from lower socio-economic groups are more likely to be obese than are women who are more affluent, but this is less certain for men $^{2}$. Some studies have shown no significant variation in BMI among adults 9 or young people ${ }^{10}$ by social class, household income group or household receipt of benefits, whereas others have shown obesity to more prevalent in adults of lower socio-economic status ${ }^{7}$. One study found that children from lower socioeconomic groups tended to be thinner ${ }^{12}$. Kinra et al. ${ }^{13}$ studied a very large and complete (95\%) population of children in Plymouth and found a high prevalence of obesity (2.5 times the national average) and an association with deprivation (by Townsend score) based on enumeration district. This was based on a wide age range (5-14year-old children) and deprivation scores for each child based on his or her place of residence.

If obesity is not associated with deprivation or concentrated geographically, there are major consequences for both policy and practical intervention measures. The aim of the present study was to utilise data from the SportsLinx project ${ }^{14}$ to investigate the distribution of children with inappropriately heavy body weight across the city of Liverpool, according to the electoral ward of the school they attended and an index of deprivation.

\section{Methods}

SportsLinx is an annual health and fitness initiative run by Liverpool City Council with other local agencies since 1997/98. Its main aims are to collect data on the health and fitness of Liverpool schoolchildren and use this information to promote and encourage sport, physical activity and healthy eating ${ }^{14}$. Ethics approval was granted for all procedures by Liverpool Children's Local Research Ethics Committee.

\section{Participants}

One year cohort from all primary schools in Liverpool was invited annually to take part in SportsLinx day at a sports centre near to the school. Between January 1998 and March 2003, trained fitness officers measured the heights and weights of 15416 children (about 58\% of all Liverpool children in that age group) aged $9-10$ years ( 7902 boys and
7514 girls) from 106 primary schools (117 total in the city). Height was recorded to the nearest $0.5 \mathrm{~cm}$ using a portable stadiometer (Seca Leicester Height Measure, Birmingham, UK). Weight was recorded to the nearest $0.5 \mathrm{~kg}$ using Seca scales (Vogel \& Halke, Germany) and children wore only T-shirt and shorts for the measurements.

\section{Categorisation of weight problems}

BMI, weight $(\mathrm{kg}) /(\text { height }(\mathrm{m}))^{2}$, was calculated and subjects categorised as overweight or obese according to internationally recognised age-related cut-off points ${ }^{15}$; overweight $=19.46-23.39 \mathrm{~kg} \mathrm{~m}^{-2}$ for boys (obese $>23.39 \mathrm{~kg} \mathrm{~m}^{-2}$ ) and $19.45-23.46 \mathrm{~kg} \mathrm{~m}^{-2}$ for girls (obese $>23.46 \mathrm{~kg} \mathrm{~m}^{-2}$ ).

\section{Mapping}

There are 33 electoral wards in Liverpool. Each school was assigned to an electoral ward using the Ordnance Survey grid reference obtained from the school's postcode. Hence each child was allocated to an electoral ward, and therefore a deprivation score, according to the school he or she attended. The catchment areas of some schools crossed wards and so a child may go to school in a ward in which he or she does not live.

The total numbers of boys and girls, and the total number of obese or overweight boys and girls, were aggregated for each ward and percentages by gender and ward calculated. The geographical information system ArcView was used to produce maps of overweight, obesity and overweight or obesity levels across Liverpool wards but only the map for overweight and obesity combined is included here. Maps were produced of the standard deviation score of the prevalence of each category of weight problem in each ward based on the mean prevalence and variance of all wards. In all analyses boys and girls were kept separate.

\section{Deprivation}

The Index of Multiple Deprivation 2000 was obtained from the Office of the Deputy Prime Minister ${ }^{16}$. It can be broken down into separate domains (income, employment, health, education, housing, access to services and child poverty) and figures are given for all electoral wards. Speke is the most deprived ward in Liverpool and the second most deprived in the country. The most affluent ward in Liverpool is Childwall, which only achieves position 2414 in the national rank order (out of 8414 wards). All children attending a school in a given electoral ward were allocated an index of multiple deprivation score based only on the ward in which their school was situated.

\section{Statistical analysis}

The data from five years (1998/99 to 2002/03) have been aggregated to increase the power of the analyses using 
SPSS software, version 11.0 (SPSS Inc., Chicago, IL, USA). Risk ratios for overweight, obesity and overweight and obesity together were calculated for boys and girls separately in each electoral ward. A test for heterogeneity was carried out ${ }^{11}$. Correlation coefficients were calculated between the proportion of children classified as overweight, obese and overweight or obese and the index of multiple deprivation and each of its separate component domains for boys and girls.

\section{Results}

Overall, more girls (1503, 20.0\%) than boys (1225, $15.3 \%)$ and were classed as overweight $(P<0.000)$ but similar additional proportions were classed as obese: $5.3 \%$ (395) of boys and 5.7\% (406) of girls $(P>0.05)$ (Table 1).

\section{Distribution of schools and participants}

Figure 1a shows the distribution of schools and Table 1 presents the total numbers of male and female children for each of the 33 wards. Some wards had more schools than others (Fig. 1b); for example, there was only one school in both Anfield and Breckfield wards but seven schools in Dingle and six in the Melrose, Kensington and Granby wards. The differences in the number of schools within wards gave an uneven spread of children between wards, as shown in Fig. 1b: from 107 in Vauxhall to over 800 in Pirrie, Dingle and Warbreck wards. This variation in cohort numbers within each ward may have influenced the reliability of the estimates of prevalence of obese or overweight children calculated by ward. However, there were no significant correlations between the number of children in each ward and the rates of overweight, obesity, or overweight or obesity (all $P>0.05$ data, not shown) or

Table 1 Proportion of overweight, obesity and overweight or obesity in boys and girls by electoral ward and sorted by indices of deprivation scores $2000^{16}$

\begin{tabular}{|c|c|c|c|c|c|c|c|c|c|}
\hline \multirow[b]{2}{*}{ Ward } & \multirow[b]{2}{*}{ Boys $(n)$} & \multirow[b]{2}{*}{ Girls $(n)$} & \multicolumn{2}{|c|}{$\begin{array}{l}\text { Overweight } \\
(\%)\end{array}$} & \multicolumn{2}{|c|}{ Obese (\%) } & \multicolumn{2}{|c|}{$\begin{array}{l}\text { Overweight or } \\
\text { obese (\%) }\end{array}$} & \multirow{2}{*}{$\begin{array}{l}\text { Rank of index of } \\
\text { multiple deprivation }\end{array}$} \\
\hline & & & Boys & Girls & Boys & Girls & Boys & Girls & \\
\hline Speke & 210 & 202 & 12.4 & 13.4 & 2.9 & 6.4 & 15.3 & 19.8 & 2 \\
\hline Everton & 145 & 137 & 13.8 & 19.7 & 7.6 & 4.4 & 21.4 & 24.1 & 4 \\
\hline Vauxhall & 60 & 47 & 16.7 & 17.0 & 10.0 & 10.6 & 26.7 & 27.6 & 6 \\
\hline Pirrie & 420 & 425 & 14.3 & 22.6 & 3.3 & 2.6 & 17.6 & 25.2 & 11 \\
\hline Granby & 182 & 175 & 17.6 & 19.4 & 4.4 & 4.6 & 22.0 & 24.0 & 13 \\
\hline Breckfield & 162 & 185 & 17.3 & 16.8 & 6.2 & 5.4 & 23.5 & 22.2 & 14 \\
\hline Melrose & 164 & 137 & 11.6 & 13.9 & 5.5 & 8.8 & 17.1 & 22.7 & 23 \\
\hline Clubmoor & 422 & 366 & 19.0 & 22.1 & 7.8 & 8.5 & 26.8 & 30.6 & 25 \\
\hline Smithdown & 146 & 144 & 15.8 & 18.8 & 6.8 & 6.9 & 22.6 & 25.7 & 29 \\
\hline Dovecot & 171 & 161 & 15.2 & 21.1 & 7.0 & 6.2 & 22.2 & 27.3 & 32 \\
\hline Netherley & 104 & 113 & 8.7 & 21.2 & 4.8 & 4.4 & 13.5 & 25.6 & 43 \\
\hline Kensington & 257 & 265 & 18.7 & 19.2 & 3.1 & 7.9 & 21.8 & 27.1 & 49 \\
\hline St. Mary's & 224 & 168 & 17.0 & 22.0 & 4.9 & 5.4 & 21.9 & 27.4 & 84 \\
\hline Valley & 385 & 355 & 13.0 & 18.9 & 3.1 & 2.8 & 16.1 & 21.7 & 128 \\
\hline Abercromby & 146 & 131 & 16.4 & 16.0 & 5.5 & 6.1 & 21.9 & 22.1 & 150 \\
\hline County & 265 & 271 & 17.7 & 18.5 & 5.3 & 3.0 & 23.0 & 21.5 & 166 \\
\hline Dingle & 417 & 415 & 14.9 & 18.3 & 4.3 & 5.5 & 19.2 & 23.8 & 211 \\
\hline Tuebrook & 288 & 301 & 18.4 & 22.3 & 2.8 & 5.6 & 21.2 & 27.9 & 232 \\
\hline Fazakerley & 277 & 260 & 13.0 & 26.5 & 5.4 & 4.6 & 18.4 & 31.1 & 257 \\
\hline Anfield & 205 & 206 & 15.6 & 21.8 & 4.4 & 3.9 & 20.0 & 25.7 & 268 \\
\hline Broadgreen & 335 & 325 & 14.0 & 16.3 & 6.3 & 3.1 & 20.3 & 19.4 & 282 \\
\hline Picton & 252 & 290 & 15.5 & 25.2 & 7.9 & 11.4 & 23.4 & 36.6 & 327 \\
\hline Old Swan & 280 & 226 & 17.1 & 23.9 & 4.6 & 8.0 & 21.7 & 31.9 & 333 \\
\hline Gilmoss & 179 & 172 & 19.0 & 18.0 & 5.6 & 5.8 & 24.6 & 23.8 & 339 \\
\hline Warbreck & 408 & 403 & 16.7 & 17.6 & 5.6 & 3.7 & 22.3 & 21.3 & 432 \\
\hline Arundel & 128 & 119 & 12.5 & 29.4 & 7.8 & 10.1 & 20.3 & 39.5 & 877 \\
\hline Croxteth & 227 & 220 & 11.0 & 21.4 & 5.3 & 5.5 & 16.3 & 26.9 & 1240 \\
\hline Allerton & 224 & 193 & 17.0 & 24.4 & 4.5 & 6.7 & 21.5 & 31.1 & 1245 \\
\hline Aigburth & 80 & 60 & 13.8 & 23.3 & 2.5 & 3.3 & 16.3 & 26.6 & 1426 \\
\hline Woolton & 129 & 128 & 17.8 & 18.0 & 6.2 & 1.6 & 24.0 & 19.6 & 2173 \\
\hline Church & 325 & 292 & 16.6 & 17.1 & 3.4 & 5.8 & 20.0 & 22.9 & 2483 \\
\hline Grassendale & 333 & 291 & 15.0 & 17.9 & 6.0 & 4.1 & 21.0 & 22.0 & 2534 \\
\hline Childwall & 352 & 331 & 13.4 & 19.0 & 2.8 & 4.8 & 16.2 & 23.8 & 2606 \\
\hline Total & 7902 & 7514 & & & & & & & * \\
\hline Mean & & & 15.3 & 20.0 & 5.3 & 5.7 & 20.6 & 25.7 & \\
\hline Standard deviation & & & 2.5 & 3.5 & 1.8 & 2.4 & 3.2 & 4.6 & \\
\hline Minimum & & & 8.7 & 13.4 & 2.4 & 1.6 & 13.5 & 19.4 & \\
\hline Maximum & & & 19.0 & 29.4 & 10.0 & 11.4 & 26.8 & 39.5 & \\
\hline
\end{tabular}

*There are 8414 wards nationally. 
(a)

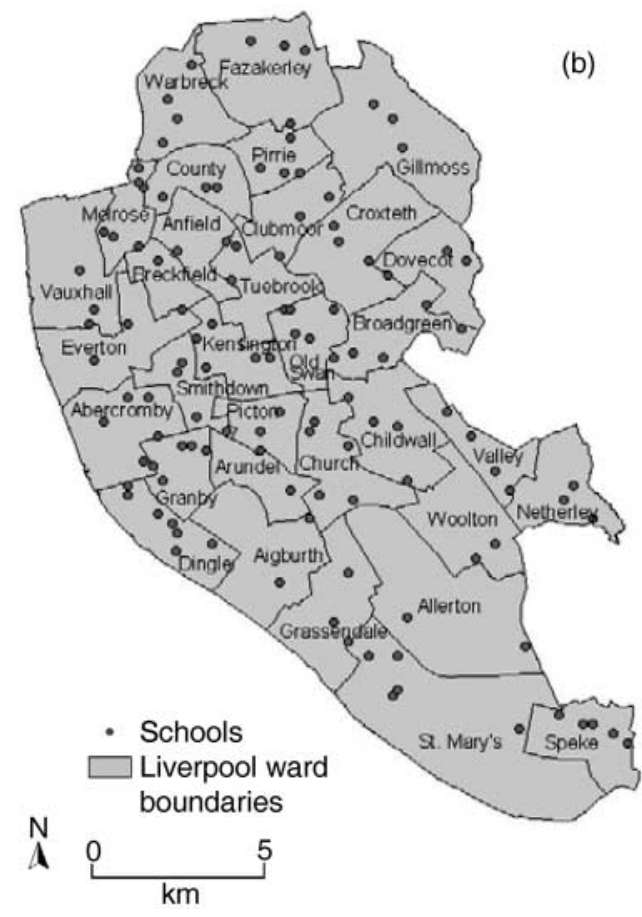

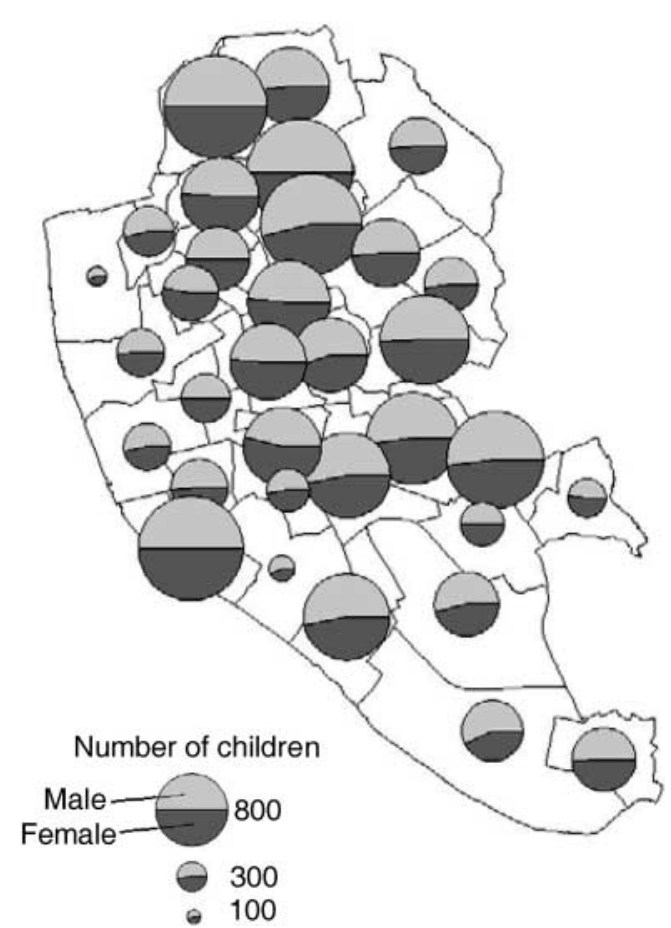

Fig. 1 (a) Location of schools within Liverpool wards; (b) size of study cohort by ward (for boys and girls)

the risk ratios for these measures (all $P>0.05$, data not shown). This suggests that the number of subjects and their distribution ${ }^{11}$ did not unduly influence the results.

\section{Relationship between weight problems and deprivation scores}

Table 1 shows the prevalence of overweight, obesity, and overweight and obesity together, for boys and girls, according to electoral ward and ranked by the index of multiple deprivation for each ward (a low score means more deprived). There was a huge range in deprivation scores and three of the most deprived wards in the country are in Liverpool. There were no significant correlations between deprivation scores and proportions of boys or girls classified as overweight, obese, or overweight and obese (all $P>0.05$, data not shown). Similarly there were no significant correlations between any component domain of the deprivation score and prevalence of weight problems for boys or girls (all $P>0.05$, data not shown).

\section{Boys}

There was no evidence of heterogeneity in risk ratios across the electoral wards for the proportion of boys judged to be overweight $(P>0.10)$, obese $(P<0.10$, $>0.05)$, or overweight or obese $(P>0.10)$. The highest percentage of combined overweight and obesity was in Clubmoor $(26.8 \%, n=113)$ and the lowest was in Netherley $(13.5 \%, n=14)$. The ward with the highest percentage of overweight was Kensington $(18.7 \%, n=48)$ and the lowest Netherley $(8.7 \%, n=9)$. Wards with the highest and lowest percentages of obesity were Picton $(7.9 \%, n=20)$ and Aigburth $(2.5 \%, n=2)$, respectively.

\section{Girls}

Unlike for the boys, there was evidence of heterogeneity in risk ratios across the electoral wards for the proportion of girls judged to be obese $(P<0.01)$ and overweight or obese $(P<0.01)$, but not overweight alone $(P>0.10)$. The highest percentage of overweight girls was in Arundel (29.4\%, $n=35$ ) and the lowest was in Speke (13.4\%, $n=27)$. Wards with the highest and lowest percentages of obesity were Picton $(11.4 \%, n=33)$ and Woolton $(1.6 \%$, $n=2$ ), respectively.

There was considerable variation in the proportion of children with weight problems across Liverpool (Table 1). The distributions of the proportion of obese or overweight boys and girls by ward were skewed - although the data for girls were strongly influenced by a small number of wards with very large percentages of obese or overweight girls $(>30 \%)$.

\section{Geographical distribution of weight problems}

Figure 2 shows the geographical distribution across Liverpool wards of children defined as overweight or obese as classified by standard deviations (SD) above and below the mean. There is some evidence of geographical heterogeneity for both boys and girls in the percentage of overweight and obesity. For example, two wards (Picton and Arundel) had overweight and obesity levels in the girls $>2$ SD above the mean, whereas the percentages for boys in these two wards were similar to the mean. For the 
(a)

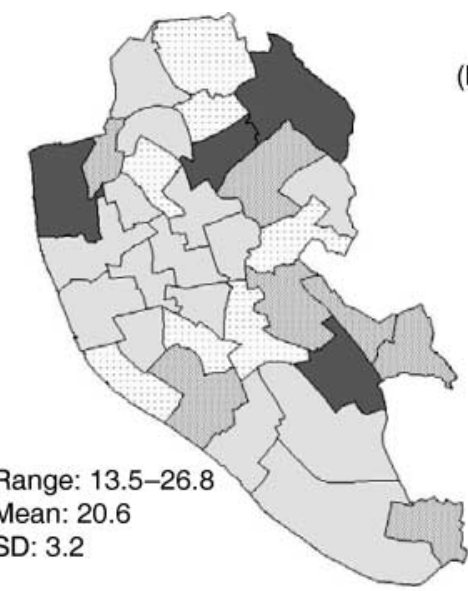

(b)
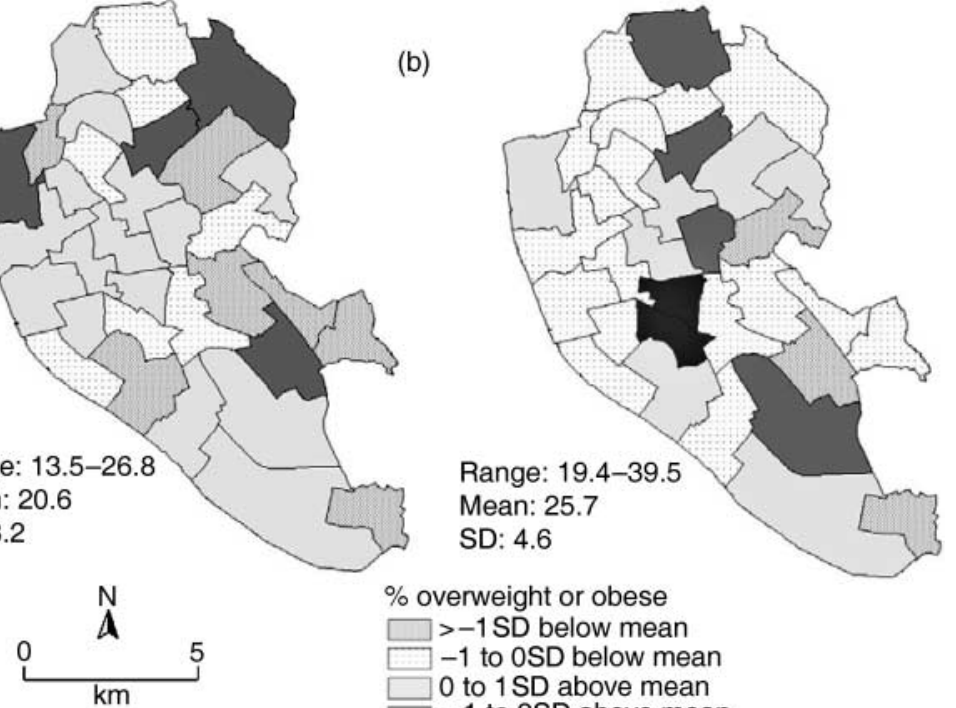

$\%$ overweight or obese

$>-1 \mathrm{SD}$ below mean

-1 to 0 SD below mean

0 to $1 \mathrm{SD}$ above mean

$>1$ to 2 SD above mean

$>2$ SD above mean

Fig. 2 Prevalence of overweight or obesity according to sex and electoral ward: (a) boys; (b) girls. SD - standard deviation

boys, only four wards had proportions of overweight and obesity more than 1SD above the mean, whereas for girls six wards were more than 1SD above the mean. There was also variation in the numbers of wards by gender with overweight and obesity percentages below the mean (14 wards below mean for boys, 20 wards below mean for girls). There were no significant correlations between the proportions of overweight, obese and overweight or obese boys and girls by ward (all $P>0.05$ ).

\section{Discussion}

BMI is reproducible and claimed to be a valid measure of childhood body $\mathrm{fat}^{17}$ and has been described as an excellent proxy of adiposity in 6-12-year-old children ${ }^{18}$. Although some muscular children might be misclassified, this is unlikely to be a significant problem. The cut-off points used are based on international data and are linked to interpretations of BMI for adults ${ }^{15}$. Even if the cut-offs used are not especially sensitive measures of 'obesity', we have identified children with extreme weights for height and the main findings of the paper are still valid.

It is not known whether the children who took part differed from those who did not. It is possible that the non-volunteers included a disproportionately high proportion of children with weight problems. The volunteer rate in most schools, however, was very high (often over 80\%) and often reduced only because whole classes were absent. The reason schools declined to take part was frequently due to co-incident inspections'. Certainly this is a very large dataset and a wide crosssection of schools and children participated.

This study found no evidence of an association between deprivation and weight problems in boys or girls. This is similar to the findings of Wright et al. ${ }^{12}$ who analysed data from a cohort born in 1947 at 9 and 13 years of age, but unlike those of Kinra et al. ${ }^{13}$ who found a strong positive correlation between obesity and deprivation in 5-14 yearolds measured in 1994-1996. Kinra et al. commented that the relationship between socio-economic deprivation and childhood obesity was unproven and contradictory. They attributed their findings to the diversity in Plymouth, the size of the dataset and deprivation ratings for individuals. Liverpool is diverse, but perhaps not as much as Plymouth, and this is a large dataset. This suggests that the lack of association in the present study arose because the study was based on classifying individuals as 'deprived' according to the school they attend from the electoral ward in which it is sited. Thus the analyses were based on deprivation scores derived not from data on who lives in each ward but on the BMI of those who attend school in each ward. This might be too crude to reveal an association but it does represent the level at which much intervention is being carried out: schools, wards and districts. In addition, it is possible that at this age the poorest children, who were more likely to be underweight at a younger age, were in the process of 'catching up' and so a relationship with obesity might only emerge later. However, such assumptions (more obesity in deprived wards) are being made in the planning of a variety of health promotion interventions which may, therefore, be unjustified depending on just how the statistics are arrived at.

Not every deprived person has a weight problem; conversely many affluent people are excessively heavy. In this study the wards with highest or lowest deprivation scores did not have the highest or lowest prevalence of children with weight problems. For example, Speke is an area of high deprivation and much intervention is being targeted there but the prevalence of weight problems was not remarkable when compared with other districts. 
Picton and Arundel, which are also deprived areas, did have very high rates of weight problems in the girls. Speke is a very open environment of wide streets, grass verges and much open space, and shops are located in only two areas. Picton and Arundel consist of densely packed terraces and roads with a shop on almost every corner.

Although the prevalence of weight problems varied for the girls (especially for obesity) across the city, this was not so for the boys. This suggests that the factors contributing to excessive weight gain (and/or their weighting) may be different in boys and girls. The interaction between the boys and girls and the environment they share could repay further investigation.

\section{Conclusions}

The prevalence of obesity was not uniformly distributed across the electoral wards for the girls but was for the boys. The prevalence of weight problems was not simply related to indices of deprivation when clustered in wards according to school attended. Therefore targeting intervention according to large administrative areas for convenience may be wasteful. There is an urgent need to explore the relationship between obesity in children and the physical and social environment, and the obesogenic differences between boys and girls, in more detail.

\section{Acknowledgements}

This project was funded by Liverpool City Council, including money from the New Opportunities Fund and the Neighbourhood Renewal Fund.

Liz Lamb, Health and Physical Activity Officer, Education, Libraries and Sport Services, Liverpool City Council, conceived, set up and runs the SportsLinx project.

Data collection was overseen by Vicci Allen and Glen Groves, Fitness Officers, Education, Libraries and Sport Services, Liverpool City Council.

\section{References}

1 Department of Health. Health Survey for England 2002: Latest Trends. London: The Stationery Office, 2003.

2 Drenowski A, Spencer SE. Poverty and obesity: the role of energy density and energy costs. American Journal of Clinical Nutrition 2004; 79: 6-16.
3 Department of Health. Nutritional Aspects of Cardiovascular Disease. London: HMSO, 1994.

4 Pate RR, Long BJ, Heath G. Descriptive epidemiology of physical activity in adolescents. Pediatric Exercise Science 1994; 6: 434-47.

5 Department of Health. The Health of the Nation. London: HMSO, 1992.

6 Department of Health. Our Healthier Nation: Saving Lives. London: HMSO, 1999.

7 House of Commons Health Committee (2004) Third Report of Session 2003-04. Obesity, Vol. 1, London: The Stationery Office, 2004.

8 International Obesity Task Force and the European Association for the Study of Obesity in Children. IOTF Obesity in Europe Childhood Section - Appendix 1. IOTF collated data for children aged around 10 years [online], 2004. Available at www.iotf.org/childhood/ euappendix.htm. Accessed 14 June 2004.

9 Ruston D, Hoare J, Henderson L, Gregory J, Bates CJ, Prentice A, et al. National Diet and Nutrition Survey: Adults aged 19 to 64 Years. London: The Stationery Office, 2004.

10 Gregory J, Lowe S, Bates CJ, Prentice A, Jackson LV, Smithers $G$, et al. National Diet and Nutrition Survey: Young People aged 4 to 18 Years. Vol. 1. Report of the Diet and Nutrition Survey. London: The Stationery Office, 2000.

11 Olsen SF, Martuzzi M, Elliot P. Cluster analysis and disease mapping - why, when and how? A step by step guide. British Medical Journal 1996; 313: 863-6.

12 Wright CM, Parker L, Lamont D, Craft AW. Implications of childhood obesity for adult health: findings from thousand families cohort study. British Medical Journal 2001; 323: $1280-4$.

13 Kinra S, Nelder RP, Lewendon GJ. Deprivation and childhood obesity: a cross-sectional study of 20,973 children in Plymouth. Journal of Epidemiology and Community Health 2000; 54: 456-60.

14 Taylor S, Hackett A, Stratton G, Lamb L. SportsLinx: improving the health and fitness of Liverpool's youth. Education \& Health 2004; 22: 3-7.

15 Cole TJ, Bellizi MC, Flegal KM, Dietz WH. Establishing a standard definition for childhood overweight and obesity worldwide: international survey. British Medical Journal 2000; 320: 1-6.

16 Office of the Deputy Prime Minister [homepage]. Indices of Deprivation 2000. Available at www.odpm.gov.uk. Accessed 9 June 2004.

17 Bellizzi MC, Deitz WH. Workshop on childhood obesity: summary of the discussion. American Journal of Clinical Nutrition 1999; 70: 173S-5S.

18 Zimmerman MB, Gubeli C, Puntener C, Molinari L. Detection of overweight and obesity in a national sample of 6-12-y-old Swiss children: accuracy and validity of reference values for body mass index from the US Centers for Disease Control and Prevention and the International Obesity Task Force. American Journal of Clinical Nutrition 2004; 79: 838-43. 